\title{
Strategi pengendalian alih fungsi lahan pertanian di Desa Pandak Gede Kabupaten Tabanan
}

\author{
Strategy to control covertion of land agriculture at Pandak Gede Village Tabanan Regency \\ Ahmad Sidiq $^{\text {a }}$ Ida A. Armeli ${ }^{\mathrm{a}}$, Ni K. A. Siwalatri ${ }^{\mathrm{a}}$ \\ ${ }^{a}$ Program Magister Arsitektur, Universitas Udayana, Kampus Unud Jimbaran Kuta, 80361, Indonesia
}

\section{Article Info:}

Received: 11 - 03 - 2020

Accepted: 18 - 05 - 2020

Keywords:

Conversion of agricultural land functions, control strategies

Corresponding Author:

Ahmad Sidiq

Program Magister Arsitektur,

Universitas Udayana;

Email:

dieq.ahmad@gmail.com

\begin{abstract}
This research was conducted to formulate a strategy to control the conversion of agricultural land based on patterns of land-use changes that occur and social changes that occur in the community of Pandak Gede Village, Tabanan Regency. The analytical method used is a mixed-method, which includes analysis of regional development, land-use suitability analysis, socio-economic analysis, socio-cultural analysis, and analysis of control strategies for agricultural land-use change. The results showed that during 2001-2010 there was a conversion of 54.03 hectares of agricultural land into residential and non-agricultural land. In 2019, the pattern of changes in land use has caused a discrepancy with the spatial pattern determined in the 2012-2032 Tabanan District Spatial Plan which is 23.56\%. The cause is a change in the structure of people's livelihoods from the agricultural sector to the trade and service sectors. Based on the sociocultural conditions of the community, alternative strategies to control the conversion of agricultural land that can be done are facilitative, reeducative, persuasive and power strategies that involve kelian adat, pekaseh, dendesa, Perbekel and government officials (head of offices and regents) as well as traditional village community groups and subak and business community.
\end{abstract}

How to cite (CSE Style $8^{\text {th }}$ Edition):

Sidiq A, Armeli IA, Siwalatri NKA. 2020. Strategi pengendalian alih fungsi lahan pertanian di Desa Pandak Gede Kabupaten Tabanan. JPSL 10(2): 329-337. http://dx.doi.org/10.29244/jpsl.10.2.329-337.

\section{PENDAHULUAN}

Kabupaten Tabanan merupakan salah satu kabupaten di Provinsi Bali yang menjadi sentral produksi pertanian. Jumlah produksi pertanian Kabupaten Tabanan berdasarkan data Badan Pusat Statistik (BPS) tahun 2018 dengan luas lahan sawah 21714 hektar menghasilkan produksi padi 211178 ton. Undang-Undang nomor 41 tahun 2009 (UU 41/2009) tentang Perlindungan Lahan Pertanian Berkelanjutan memberikan amanat melindungi kawasan dan lahan pertanian berkelanjutan serta menjamin ketersediaan lahan pangan berkelanjutan. Lahan pertanian pangan bekelanjutan adalah bidang lahan pertanian yang ditetapkan untuk dilindungi dan dikembangkan secara konsisten guna menghasilkan pangan pokok bagi kemandirian, ketahanan dan kedaulatan pangan nasional.

Kecamatan Kediri dalam rencana sistem perkotaan Kabupaten Tabanan menjadi wilayah yang berfungsi sebagai kawasan perkotaan serta kawasan penyangga antar perkotaan dan kawasan perkotaan di sekitarnya, dan Desa Pandak Gede merupakan salah satu desa di Kecamatan Kediri. Berdasarkan hasil pengolahan peta penggunaan lahan Rencana Tata Wilayah Desa Pandak Gede tahun 2001-2011 diperoleh data luasan lahan 
sawah 240.40 hektar dan luasan lahan permukiman 51.06 hektar pada tahun 2001. Data luasan hasil pengolahan citra satelit tahun 2019 menunjukkan luasan lahan sawah 186.47 hektar dan lahan permukiman 81.05 hektar. Hal ini menunjukkan adanya pengurangan luas lahan pertanian dalam 18 tahun terakhir sebesar 54.03 hektar dan peningkatan lahan permukiman sebesar 30.09 hektar. Dari kondisi tersebut dapat dipertanyakan apakah telah terjadi alih fungsi terhadap lahan pertanian di Desa Pandak Gede.

Posisi Desa Pandak Gede yang berada di jalur pariwisata Tanah Lot serta nilai ekonomi tanah yang tinggi dapat mendorong kecenderungan perkembangan wilayah yang lebih cepat. Jumlah penduduk di Desa Pandak Gede meningkat dari tahun 2001 sebanyak 4512 jiwa menjadi 5928 jiwa pada tahun 2018. Pertambahan jumlah penduduk menyebabkan perubahan jumlah dan persebaran wilayah permukiman, perubahan struktur mata pencaharian yang diikuti oleh berkurangnya luas lahan pertanian dapat menjadi indikasi awal terjadinya alih fungsi lahan pertanian menjadi lahan non-pertanian.

Melihat perkembangan kecenderungan perubahan penggunaan lahan dan pertumbuhan penduduk di Desa Pandak Gede, diperlukan penelitian untuk mengetahui terjadinya perubahan penggunaan lahan apakah telah sesuai dengan rencana tata ruang yang berlaku atau apakah ada ketidaksesuaian dengan rencana tata ruang yang berlaku dan bagaimana strategi pengendalian alih fungsi lahan pertanian tersebut.

\section{METODE}

\section{Lokasi dan Waktu Penelitian}

Lokasi penelitian adalah Desa Pandak Gede Kecamatan Kediri Kabupaten Tabanan. Desa ini berbatasan dengan Desa Pandak Bandung di sebelah utara, Desa Beraban di sebelah selatan, Desa Nyambu dan Desa Buwit di sebelah timur serta Desa Beraban dan Desa Nyitdah di sebelah barat. Desa Pandak Gede dilalui oleh jalur utama yang menghubungkan Kediri-Tanah Lot. Desa ini dipilih sebagai lokasi penelitian dengan pertimbangan bahwa dalam rencana sistem perkotaan, Desa Pandak Gede merupakan kawasan penyangga perkotaan. Apabila melihat proses perkembangan kota, kawasan-kawasan permukiman mengalami kecenderugan berkembang di kawasan penyangga perkotaan. Penelitian dilaksanakan selama 10 bulan dari tanggal 14 Februari 2019 sampai tanggal 14 Desember 2019.

\section{Metode Pengumpulan Data}

Teknik pengumpulan data yang digunakan dalam penelitian ini adalah wawancara, observasi dan dokumentasi. Wawancara yang dilakukan selama penelitian terbagi kedalam dua tahapan. Tahap pertama adalah wawancara yang sifatnya tidak terstruktur, dilakukan pertama kali dengan menemui perwakilan dari perangkat desa (sekretaris desa) untuk menemukan dan mengenali isu-isu dan permasalahan secara umum. Wawancara tahap selanjutnya dilakukan secara terstruktur, lebih mendalam dan mengulas isu-isu yang ditemukan pada wawancara tahap awal. Observasi dilakukan untuk membuktikan informasi-informasi yang diperoleh selama wawancara. Observasi juga digunakan teknik untuk melacak bidang-bidang tanah yang mengalami perubahan penggunaan lahan di lapangan berdasarkan hasil overlay peta-peta penggunaan tanah. Dokumentasi diperlukan sebagai sarana untuk merekam hasil wawancara maupun hasil pengamatan selama penelitian.

\section{Data dan Sumber Data}

Data yang digunakan berupa data primer dan data sekunder. Data primer berupa hasil wawancara dengan sumbernya adalah perwakilan dari perangkat desa (sekretaris desa, bendesa adat, pekaseh dan kelian) dan hasil observasi berupa pengamatan langsung penggunaan lahan pertanian dan non pertanian, hasilnya berupa fotofoto dokumentasi penggunaan lahan saat penelitian. Data sekunder berupa data time series kependudukan dan peta-peta penggunaan lahan dalam rentang waktu 2001 hingga 2019. Sumber data sekunder adalah instansi yang pelaksanaan tugasnya terkait dengan isu dan permasalahan penelitian, yaitu BAPPEDA, Kantor Agraria 
dan Tata Ruang/Badan Pertanahan Nasional (ATR/BPN), Badan Pusat Statistik (BPS), Kantor Desa dan lembaga terkait lainnya.

\section{Metode Analisis Data}

Metode analisis yang digunakan dalam penelitian ini adalah triangulasi. Metode ini merupakan penggabungan antara metode kualitatif dan metode kuantitatif yang digunakan secara bersama-sama dalam penelitian (Gunawan, 2013). Teknik triangulasi yang digunakan yaitu triangulasi sumber dan triangulasi metode. Triangulasi sumber dilakukan saat melakukan wawancara dengan memadukan dan menanyakan kembali berbagai isu-isu kepada beberapa narasumber yang berbeda. Hal ini dilakukan untuk mengetahui kebenaran informasi dan menambah pemahaman dalam penarikan kesimpulan. Triangulasi metode dilakukan dengan memadukan hasil-hasil pengolahan data dari peta-peta penggunaan lahan sehingga diketahui pola perkembangannya. Hasilnya dipadukan dan ditanyakan ulang kepada narasumber.

\section{HASIL DAN PEMBAHASAN}

\section{Dinamika Perubahan Penggunaan Lahan Desa Pandak Gede}

Kecenderungan perubahan pengunaan lahan terjadi hampir di semua banjar meliputi Banjar Panti, Banjar Saba, Banjar Pangkung, Banjar Batan Poh, Banjar Belatungan, Banjar Taman Sari, Banjar Kebon, dan Banjar Pasti. Banjar Kebon dan Banjar Pasti adalah wilayah yang cenderung mengalami sedikit perubahan penggunaan lahan, sebagaimana ditunjukkan Gambar 1.

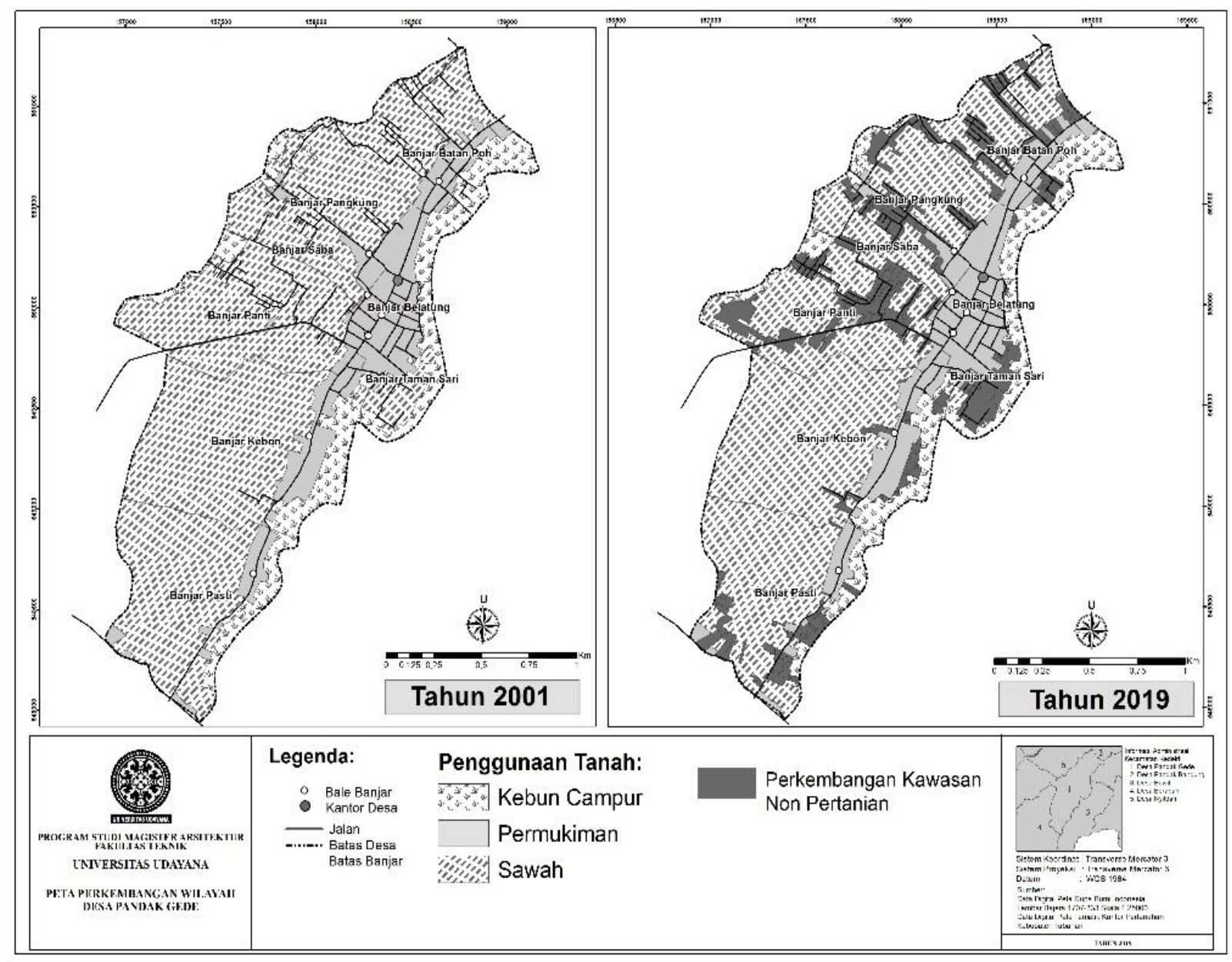

Gambar 1 Peta perkembangan wilayah Desa Pandak Gede tahun 2001-2019

Sumber: Analisis, 2019 


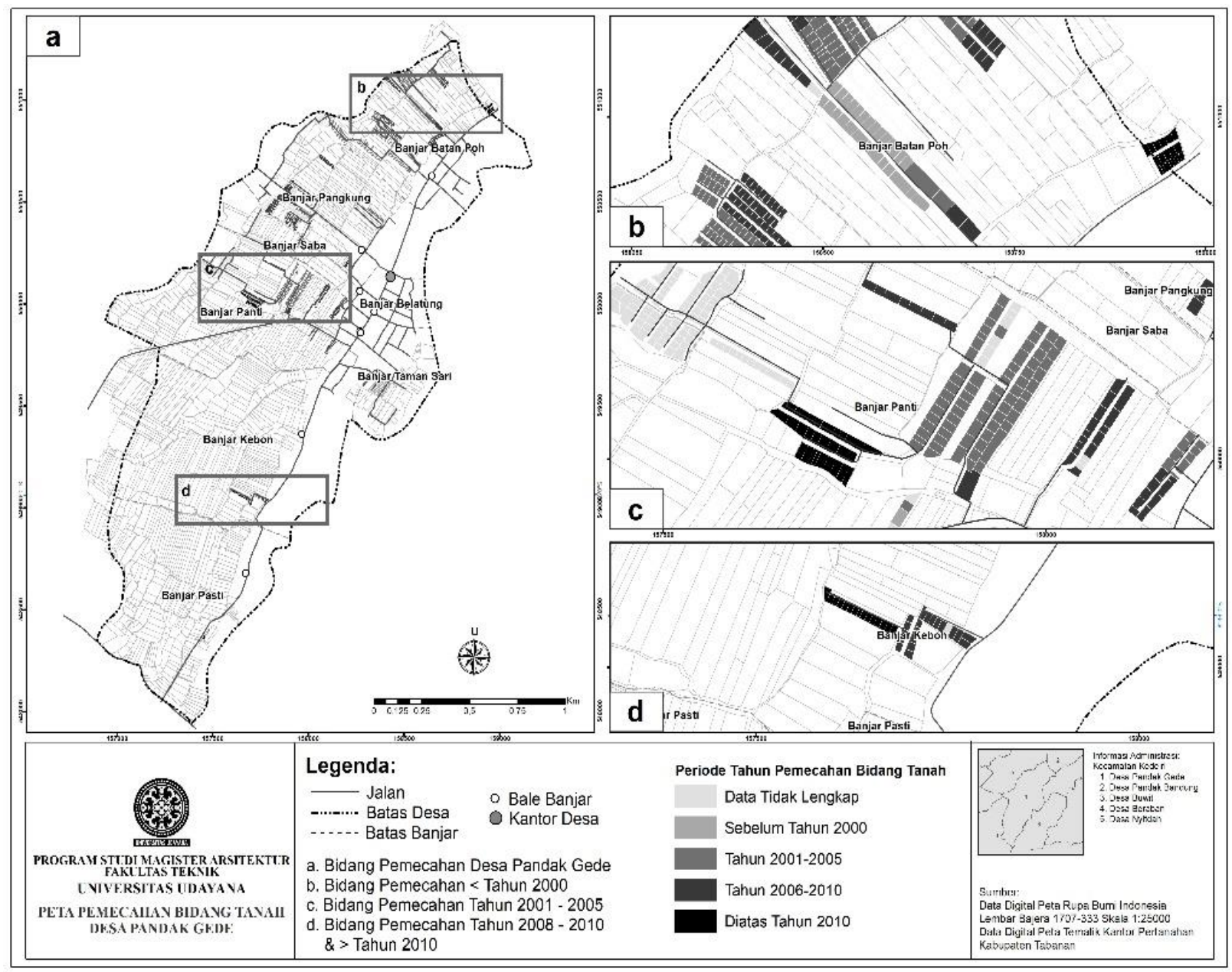

Gambar 2 Peta pemecahan bidang tanah Desa Pandak Gede 2001-2019 (Sumber: Kantor pertanahan Kabupaten Tabanan 2019, Analisis 2019)

Bertambahnya jumlah penduduk dipengaruhi oleh pembukaan lahan pertanian menjadi lahan-lahan permukiman. Hal ini terjadi dalam rentang waktu 2001 sampai dengan 2010 (sebelum RTRW Kabupaten Tabanan 2012-2032). Apabila dicermati berdasarkan sampel penelitian, jumlahnya mencapai 92\% proses pemecahan bidang tanah terjadi dibawah tahun 2010 sebagaimana ditunjukkan pada Gambar 2. Luas lahan pertanian terhadap luas wilayah Desa Pandak Gede dari tahun 2001 hingga 2019 berkurang dari 72\% (240.50 ha) menjadi $56 \%$ (186.47 ha).

\section{Kesesuaian Penggunaan Lahan dengan RTRW Kabupaten Tabanan 2012-2032}

Berdasarkan overlay peta penggunaan lahan tahun 2019 dengan rencana pola ruang dalam RTRW Kabupaten Tabanan 2012-2032, diperoleh hasil bahwa penggunaan lahan yang sesuai dengan rencana pola ruang sebesar $76.44 \%$ ( 257.16 ha) dan penggunaan lahan yang tidak sesuai dengan rencana pola ruang sebesar $23.56 \%$ (79.28 ha). 


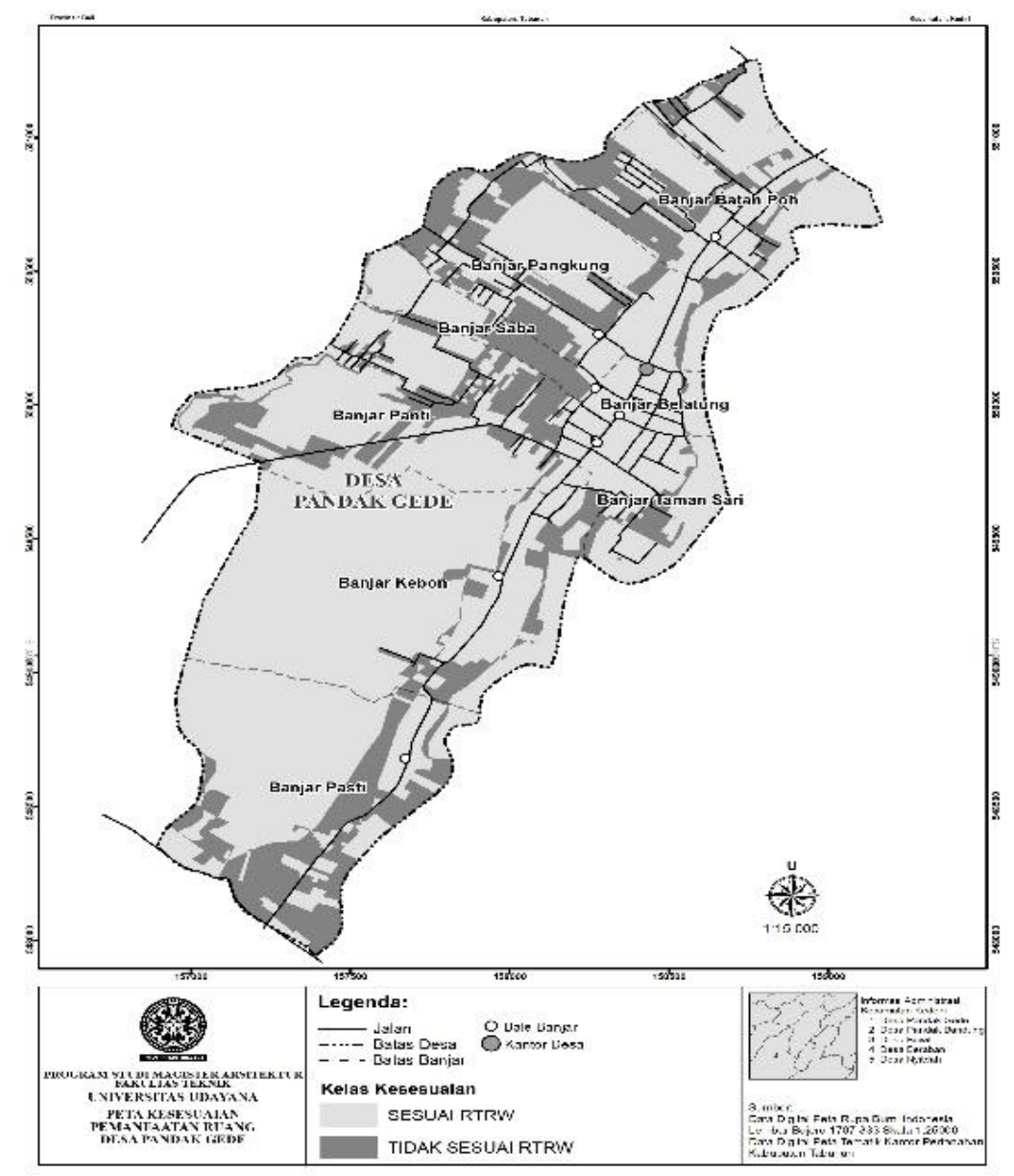

Gambar 3 Peta kesesuaian penggunaan lahan Desa Pandak Gede (Sumber: Analisis, 2019)

\section{Kondisi Sosial Ekonomi Desa Pandak Gede}

Jumlah penduduk di desa Pandak Gede tahun 2001 sampai dengan 2018 meningkat $31.38 \%$ dengan persentase peningkatan yang besar terjadi pada kurun waktu tahun 2001 hingga 2012 yaitu 28.8\%. Peningkatan jumlah penduduk ini diikuti pergeseran struktur mata pencaharian penduduk dari pertanian ke sektor jasa. Antara tahun 2001 sampai dengan 2017, jumlah penduduk yang bekerja pada sektor pertanian berkurang dari $60 \%$ menjadi $27 \%$, dan jumlah penduduk yang bekerja pada sektor jasa dari $22 \%$ tahun 2001 menjadi $67 \%$ tahun 2018. Kondisi ini memperjelas terjadinya pergeseran struktur mata pencaharian penduduk dari pertanian ke perdagangan dan jasa.

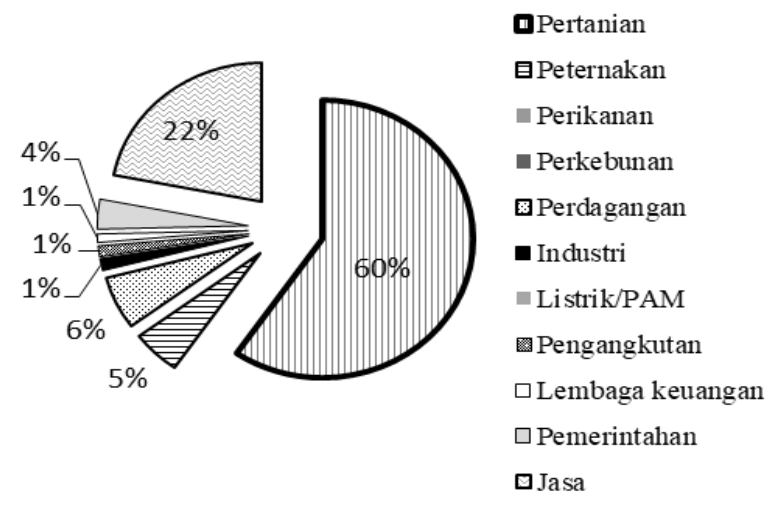

Gambar 4 Proporsi jumlah penduduk Desa Pandak Gede Tahun 2001 berdasarkan mata pencaharian (Sumber: Analisis, 2019) 


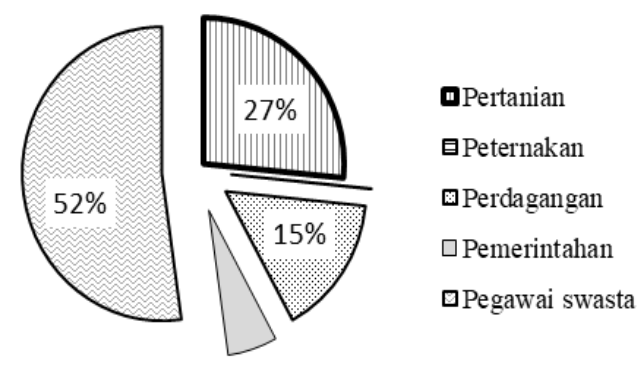

$6 \%$

Gambar 5 Proporsi jumlah penduduk Desa Pandak Gede Tahun 2017 berdasarkan mata pencaharian (Sumber: Analisis, 2019)

Struktur kepemilikan lahan yang dulunya lahan pertanian di Desa Pandak Gede saat ini 29\% lahan telah dikuasai oleh penduduk dari luar Kecamatan Kediri/luar Kabupaten Tabanan. Bidang-bidang tanah tersebut adalah bidang-bidang tanah yang sudah berubah menjadi kawasan perumahan. Lahan pertanian yang masih dikuasai oleh warga Desa Pandak Gede adalah 49\% yang terdiri dari 83\% warga Desa Adat Pandak Gede dan $17 \%$ warga Desa Adat Beraban.
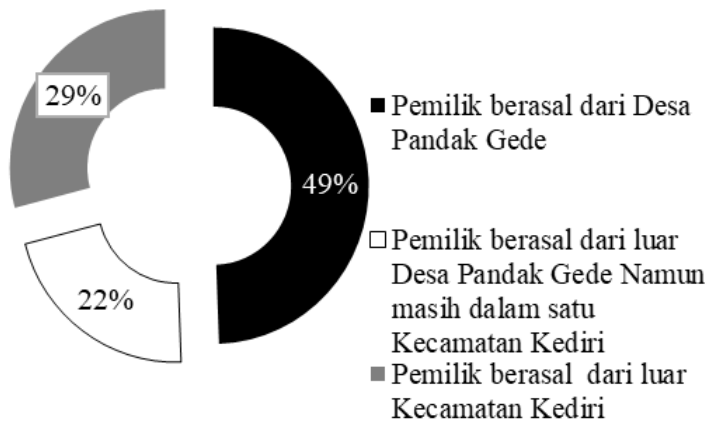

Gambar 6 Proporsi kepemilikan lahan pertanian di Desa Pandak Gede (Sumber: Analisis, 2019)

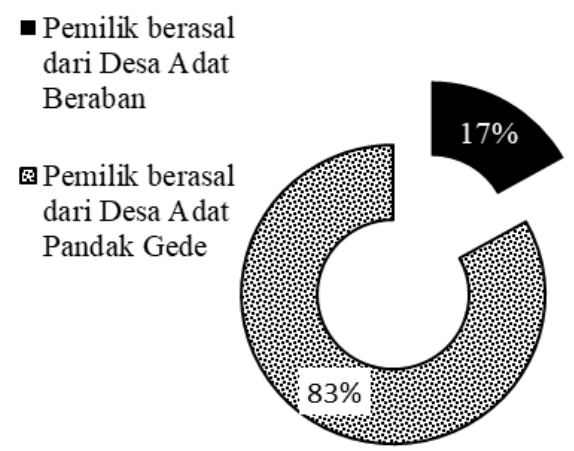

Gambar 7 Persentase kepemilikan lahan pertanian pemilik berasal dari Desa Pandak Gede (Sumber:

Analisis, 2019)

\section{Kondisi Sosial-Budaya Desa Pandak Gede dalam Pengendalian Alih Fungsi Lahan Pertanian}

Desa adat memiliki peran dalam pengendalian alih fungsi lahan pertanian. Perangkat yang digunakan dalam pengendalian tersebut adalah awig-awig, baik yang tertulis maupun yang belum tertulis. Banjar dan subak membatasi proses pemecahan bidang tanah di lahan pertanian dan perubahan penggunaan lahan di lahan pertanian dengan tetap memperhatikan RTRW Kabupaten Tabanan 2012-2032. Kondisi sosial budaya di Desa 
Pandak Gede menjadi faktor yang menghambat laju alih fungsi lahan pertanian. Hal ini dapat dilihat dari kesadaran masyarakat yang diwujudkan dalam bentuk awig-awig. Desa dinas tidak serta merta mengizinkan proses pemecahan bidang tanah di lahan pertanian sebelum struktur masyarakat dibawahnya memberikan izin. Pemecahan bidang tanah di lahan pertanian membutuhkan persetujuan pekaseh dan kelian banjar. Apabila tidak mendapatkan izin dari prajuru desa tersebut maka proses pemecahan bidang tanah tidak dapat dilanjutkan. Pekaseh dan kelian adat memiliki kewenangan berdasarkan awig-awig dan sejalan dengan Peraturan Daerah Provinsi Bali Nomor 4 Tahun 2019 tentang Desa Adat di Bali.

Kesepakatan krama adat dan kewenangan-kewenangan prajuru desa dalam pengendalian alih fungsi lahan sejalan dengan tindakan sosial yang mengonstruksi kewenangan legal-rasional. Menurut Damsar (2015), kewenangan legal-rasional yaitu kewenangan didasarkan atas komitmen terhadap seperangkat peraturan yang diundangkan secara resmi dan diatur secara impersonal. Adapun faktor sosial budaya sebagai faktor penghambat laju alih fungsi lahan pertanian sebagai wujud adanya faktor kepentingan-kepentingan yang telah tertanam dengan kuat (versted interest) dan rasa khawatir akan terjadinya kegoyahan pada integritas kebudayaan (Martono, 2016). Faktor ini terlihat jelas dalam bentuk upaya untuk tetap mempertahankan lingkungan serta dorongan kekhawatiran terhadap perubahan struktur masyarakat yang dapat didominasi olah pendatang, yang dapat berdampak pada kepentingan adat.

\section{Strategi Pengendalian Alih Fungsi Lahan Pertanian}

Tindakan sosial merupakan suatu tindakan individu yang memiliki arti atau makna subjektif bagi dirinya dikaitkan dengan orang lain. Terdapat empat tipe tindakan sosial menurut Damsar (2015), yaitu tindakan rasional instrumental (instrumentally rational action), tindakan rasional nilai (value rationa action), tindakan afektif (affectual action), tindakan tradisional (traditional action).

Menurut Wirawan (2014) teori pilihan rasional memandang bahwa kehidupan sosial adalah hasil pilihan rasional. Tindakan rasional berkaitan langsung dengan niat, tetapi aktornya dapat bertindak secara tidak rasional. Pilihan merupakan sebuah proses optimalisasi, pilihan dianggap sebagai sesuatu yang rasional. Damsar (2015) mengatakan tindakan sosial dari berbagai individu mengonstruksi suatu bangunan dasar bagi struktur-struktur sosial yang lebih besar dan dapat mengonstruksi kewenangan tertentu, dengan tipe tipologi kewenangan sebagai berikut.

1. Kewenangan tradisional, yaitu kewenangan yang didasarkan atas tradisi, kebiasaan, kekudusan aturan dan kekuatan zaman dahulu.

2. Kewenangan karismatik, yaitu kewenangan yang diperoleh seseorang karena dipandang memiliki kualitas kepribadian individu yang extraordinary (luar biasa) dan diperlakukan sebagai orang yang dianugerahi kekuatan-kekuatan dan kualitas supernatural (adiduniawi), superhuman (adiinsani), dan exceptional (pengecualian).

3. Kewenangan legal-rasional yaitu kewenangan didasarkan atas komitmen terhadap seperangkat peraturan yang diundangkan secara resmi dan diatur secara impersional.

Martono (2016) menjelaskan bahwa sasaran perubahan sosial dapat ditujukan kepada individu, kelompok masyarakat tertentu atau masyarakat secara keseluruhan yang akan dikenai perubahan. Sasaran perubahan sosial tersebut sebagai berikut.

1. Individu sebagai sasaran perubahan sosial

Strategi perubahan yang melibatkan individu sebagai agen perubahan harus memilih individu yang benarbenar memiliki pengaruh di dalam kelompok tersebut, karena individu-individu tersebut diharapkan mampu mengubah kelompoknya secara perlahan.

2. Kelompok sebagai sasaran perubahan sosial

Perubahan suasana akan mempengaruhi individu. Nilai, sikap dan perilaku individu akan diubah melalui perubahan struktur sosial atau melalui perubahan kelompok yang menjadi tempat individu berpikir dan bertindak. 
3. Struktur sebagai sasaran perubahan sosial

Struktur sosial mencakup pola stratifikasi sosial dan diferensiasi sosial. Perubahan ditingkat struktur dapat meliputi perubahan dalam sistem pembagian kelas sosial, perubahan vokasional anggota masyarakat atau perubahan norma dan nilai.

Martono (2016) menjelaskan lebih lanjut terkait strategi-strategi perubahan sosial tersebut sebagai berikut.

1. Strategi Fasilitatif

Agen perubahan sosial dalam strategi ini bertindak sebagai fasilitator yang menyediakan berbagai sumber daya, informasi, dan sebagai sarana konsultasi.

2. Strategi Re-edukatif

Strategi ini digunakan apabila ada hambatan-hambatan sosial budaya dalam penerimaan suatu inovasi, terutama berkaitan dengan kelemahan pengetahuan atau pendidikan dan keterampilan dalam memanfaatkan suatu inovasi.

3. Strategi Persuasif

Startegi ini merupakan upaya melakukan perubahan masyarakat dengan cara membujuk masyarakat melakukan perubahan.

4. Strategi Kekuasaan

Strategi yang digunakan untuk melakukan perubahan dengan cara paksaan, menggunakan ancaman.

Strategi ini akan berhasil apabila agen perubahan memiliki sumber daya untuk memberikan hadiah atau sanksi tertentu terhadap kelompok sasaran perubahan.

Kesepakatan bersama yang dituangkan secara legal-rasional menjadi salah satu strategi dalam pengendalian alih fungsi lahan pertanian. Kesepakatan tersebut merupakan tindakan rasional instrumental untuk mendorong tercapainya pengendalian alih fungsi lahan pertanian. Kesepakatan secara legal-rasional ini berbentuk awig-awig sesuai dengan ketentuan Peraturan Daerah Provinsi Bali Nomor 9 tahun 2012 tentang Subak dan nomor 4 tahun 2019 tentang Desa Adat di Bali. Alternatif strategi pengendalian alih fungsi lahan pertanian mengacu pada strategi dasar perubahan sosial meliputi strategi fasilitatif, strategi reedukatif, strategi persuasif dan strategi kekuasaan.

Strategi fasilitatif merupakan upaya memfasilitasi penyampaian informasi peraturan melalui agen-agen perubahan dengan sasaran individu, kelompok dan struktur. Individu yang berperan dalam implementasi ini meliputi perangkat desa, bendesa adat, klian, pekaseh dan tokoh-tokoh masyarakat yang memiliki visi pelestarian. Kelompok-kelompok yang berperan antara lain subak dan desa adat, sedangkan secara struktur adalah institusi dan dinas-dinas pemerintah.

Strategi reedukatif merupakan upaya peningkatan pemahaman dan pengetahuan terhadap informasi rencana tata ruang dan alih fungsi lahan pertanian. Sasaran strategi ini tidak hanya masyarakat, melainkan kelompok-kelompok masyarakat, kelompok-kelompok usaha serta pegawai pemerintahan yang memiliki tugas berkaitan dengan implementasi kebijakan tersebut. Pemahaman yang dimaksud meliputi penguasaan norma dan peraturan yang berlaku, serta tata cara perizinan sesuai dengan norma-norma dan peraturan-peraturan yang berlaku.

Strategi persuasif merupakan upaya pendekatan kepada masyarakat pemilik lahan pertanian. Upayaupaya ini dilakukan agar masyarakat secara sadar menerima dan melaksanakan kebijakan pemerintah tanpa paksaan. Pendekatan-pendekatan dilakukan kepada individu maupun kelompok-kelompok masyarakat desa adat dan subak. Secara struktur senantiasa dilakukan penguatan-penguatan kebijakan dalam pengendalian alih fungsi lahan pertanian dalam bentuk peraturan daerah dan peraturan bupati.

Strategi kekuasaan adalah strategi pemaksaan masyarakat untuk mengikuti peraturan yang berlaku. Strategi ini mencerminkan pengambilan keputusan sehingga yang berperan sebagai pengambil keputusan dalam hal ini antara lain kelian adat, pekaseh, dendesa, perbekel, kepala dinas dan bupati. Pelaksana yang bertugas tetap berpegang pada peraturan yang berlaku. 


\section{KESIMPULAN}

Pertambahan jumlah penduduk di Desa Pandak Gede seiring dengan pergeseran struktur mata pencaharian penduduk dan kepemilikan lahan pertanian telah menyebabkan terjadinya alih fungsi lahan pertanian menjadi kawasan permukiman. Kondisi ini menyebabkan sebagian penggunaan lahan tidak sesuai dengan pola ruang yang telah ditetapkan dalam Rencana Tata Ruang Wilayah Kabupaten Tabanan 2012-2032. RTRW Kabupaten Tabanan 2012-2032 yang telah ditetapkan hendaknya juga ditindaklanjuti dengan penetapan Rencana Detail Tata Ruang Kota (RDTRK). RDTRK sifatnya lebih operasional digunakan dalam proses perizinan daripada RTRW. Produk legal formal ini seiring dengan penguatan kelembagaan sosial budaya masyarakat di dalam mengendalikan jual beli lahan yang dilakukan oleh anggota masyarakat yang dapat menyebabkan alih fungsi lahan pertanian diharapkan dapat menjadi strategi pengendalian alih fungsi lahan pertanian di Desa Pandak Gede tanpa mengurangi peran desa tersebut sebagai pusat lingkungan sebagaimana telah ditetapkan dalam rencana pengembangan wilayah Kabupaten Tabanan Tahun 2012-2032.

\section{DAFTAR PUSTAKA}

[BPS] Badan Pusat Statistik. Kabupaten Tabanan Dalam Angka 2018. Tabanan (ID): Badan Pusat Statistik Kabupaten Tabanan.

[BPS] Badan Pusat Statistik. Kabupaten Tabanan Dalam Angka 2019. Tabanan (ID): Badan Pusat Statistik Kabupaten Tabanan.

Damsar. 2015. Pengantar Teori Sosiologi. Jakarta (ID): Prenada Media Group.

Gunawan, Imam. 2013. Metode Penelitian Kualitatif Teori dan Praktek. Jakarta (ID): Bumi Aksara.

Kantor Desa Pandak Gede. Profil Pembangunan Desa Pandak Gede Tahun 2017. Tabanan (ID): Kantor Desa Pandak Gede.

Kantor Desa Pandak Gede. Rencana Tata Wilayah Desa Pandak Gede Tahun 2001-2011. Tabanan (ID): Kantor Desa Pandak Gede.

Martono. 2016. Sosiologi Perubahan Sosial Perspektif Klasik, Modern, Postmodern, dan Poskolonial. Jakarta (ID): Raja Grafindo Persada.

Pemerintah Kabupaten Tabanan. 2012. Peraturan Daerah Kabupaten Tabanan Nomor 11 Tahun 2012 tentang Rencana Tata Ruang Wilayah (RTRW) Kabupaten Tabanan Tahun 2012-2032. Lembaran Daerah Kabupaten Tabanan tahun 2012, No. 28. Tabanan (ID): Sekretariat Daerah.

Pemerintah Provinsi Bali. 2012. Peraturan Daerah Provinsi Bali Nomor 9 Tahun 2012 tentang Subak. Lembaran Daerah Provinsi Bali tahun 2012 No. 9. Denpasar (ID): Sekretariat Daerah.

Pemerintah Provinsi Bali. 2019. Peraturan Daerah Provinsi Bali Nomor 4 Tahun 2019 tentang Desa Adat di Bali. Lembaran Daerah Provinsi Bali Tahun 2019, No.4. Denpasar (ID): Sekretariat Daerah.

Pemerintah Republik Indonesia. 2009. Undang-Undang Nomor 41 Tahun 2009 tentang Perlindungan Lahan Pertanian Pangan Berkelanjutan. Lembaran Negara RI Tahun 2009, No. 149. Jakarta (ID): Sekretariat Negara.

Wirawan. 2014. Teori-Teori Sosial Dalam Tiga Paradigma Fakta Sosial, Definisi Sosial dan Perilaku Sosial. Jakarta (ID): Prenada Media Group. 